\title{
Class-D amplifier design and performance for driving a Piezo Actuator Drive servomotor.
}

\author{
Zsurzsan, Tiberiu-Gabriel; Zhang, Zhe; Andersen, Michael A. E.; Andersen, Nils Axel
}

Published in:

Proceedings of 2016 IEEE International Conference on Industrial Technology

Link to article, DOI:

10.1109/ICIT.2016.7474902

Publication date:

2016

Document Version

Peer reviewed version

Link back to DTU Orbit

\section{Citation (APA):}

Zsurzsan, T-G., Zhang, Z., Andersen, M. A. E., \& Andersen, N. A. (2016). Class-D amplifier design and performance for driving a Piezo Actuator Drive servomotor. In Proceedings of 2016 IEEE International Conference on Industrial Technology (pp. 1068-1072). IEEE. https://doi.org/10.1109/ICIT.2016.7474902

\section{General rights}

Copyright and moral rights for the publications made accessible in the public portal are retained by the authors and/or other copyright owners and it is a condition of accessing publications that users recognise and abide by the legal requirements associated with these rights.

- Users may download and print one copy of any publication from the public portal for the purpose of private study or research.

- You may not further distribute the material or use it for any profit-making activity or commercial gain

- You may freely distribute the URL identifying the publication in the public portal 


\title{
Class-D amplifier design and performance for driving a Piezo Actuator Drive servomotor
}

\author{
Gabriel T. Zsurzsan*, Zhe Zhang, Michael M.A. Andersen and Nils A. Andersen \\ Department of Electrical Engineering, Technical University of Denmark \\ Denmark \\ E-mail: *tgzsur@elektro.dtu.dk
}

\begin{abstract}
This paper investigates the behavior of piezoelectric stacks in a Piezoelectric Actuator Drive (PAD) motor, which shows non-linear equivalent impedance and has a dramatic impact on the overall system performance. Therefore, in this paper, the piezo stackt's model is discussed and an improved large signal model is proposed and verified by measurement. Finally, a Class-D amplifier as a power driver and its associated closed-loop control are implemented and tested to control PAD drive effectively.
\end{abstract}

Index Terms-Piezoelectricity, motor, control

\section{INTRODUCTION}

$\mathbf{T}$ HE The Piezoelectric Actuator Drive (PAD) is a new type of electrical motor that employs piezoelectric multilayer actuators which have inherent capacitive behavior [1]-[5]. The PADs internal structure is shown in Fig. 1. Through voltage excitation, the multilayer actuators expand and contract linearly along their length [6]-[8]. Therefore, by applying a sinusoidal voltage to the actuators on one axis and a $90^{\circ}$ phase-shift version to the other actuators, the resulting spacevector and trajectory will be circular, and the corresponding waveforms are illustrated in Fig. 2 respectively. In order to control PAD drives effectively and efficiently, in this paper, besides small signal model, an improved large signal model of piezoelectric actuators equipped in PADs is proposed to estimate the apparent power transferring through the power driver accurately. A switched-mode Class-D power amplifier [9], [10] i.e. a synchronous Buck converter is employed as the driver generating the needed two channel phase-shifted sinusoidal outputs. The analysis and design of the power driver and its associated average current mode closed-loop controller implemented digitally are presented. Finally, the analysis is verified by the measurement results from a laboratory prototype.

\section{Piezoelectric STACK ACTUATORS}

Considering piezoelectric stack a constant load capacitance allows for designing the power amplifier in terms of component stresses, switching frequency and efficiency. However, neglecting the non-linear nature of the piezo stack impedance hides many important phenomena. To better describe the piezo stacks behavior, both small signal (SS) and large signal (LS) impedance are measured, which can be used for a mathematical analysis of system and more importantly for power driver design. The SS capacitance and loss tangent of a

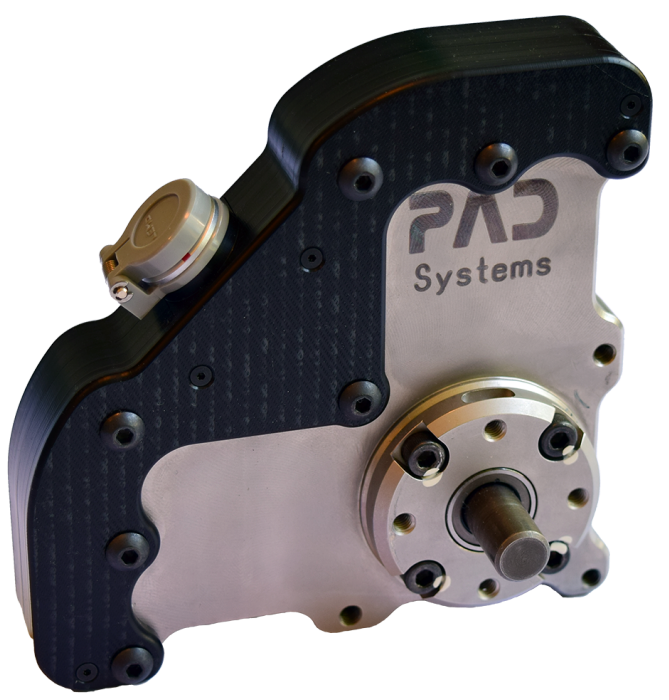

(a)

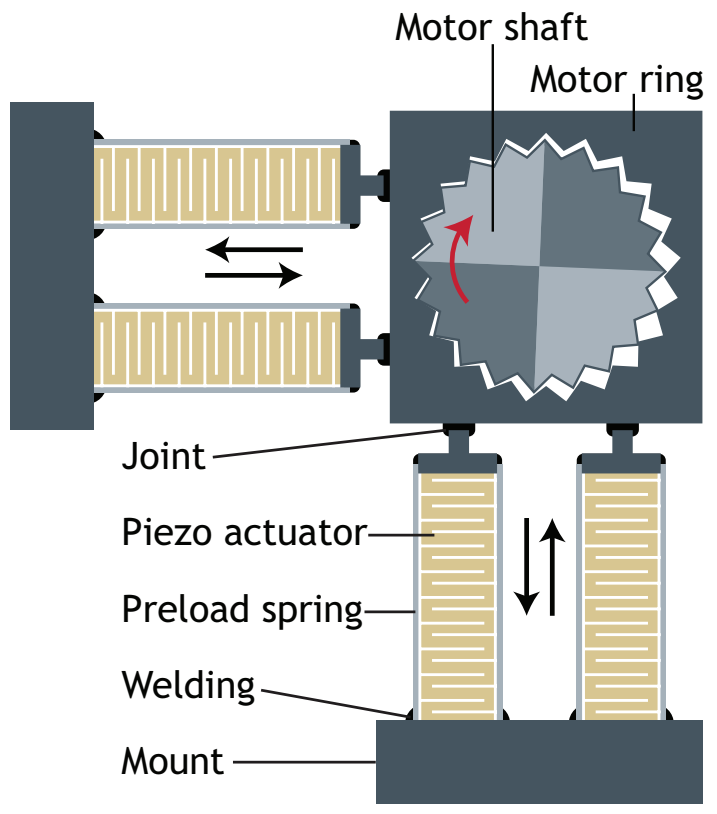

(b)

Fig. 1. PAD motor (a) and its internal structure (b). The internal structure of the PAD is made up of 4 PMA actuators acting against a motor ring, which in turn is coupled to the shaft through a micromechanical gearing. The pitch of the gears is $100 \mu \mathrm{m}$. 


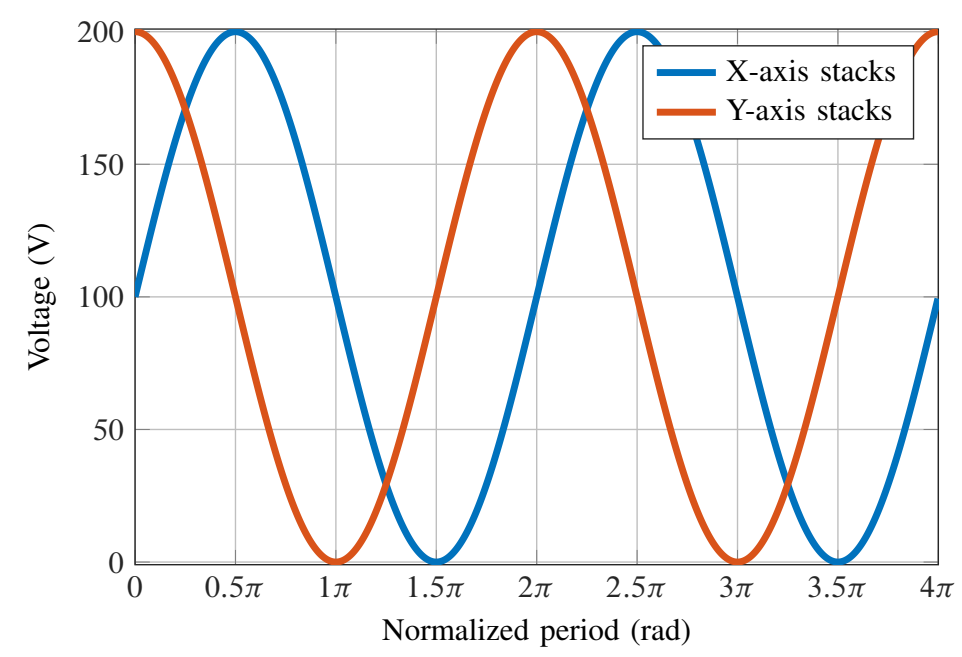

(a)

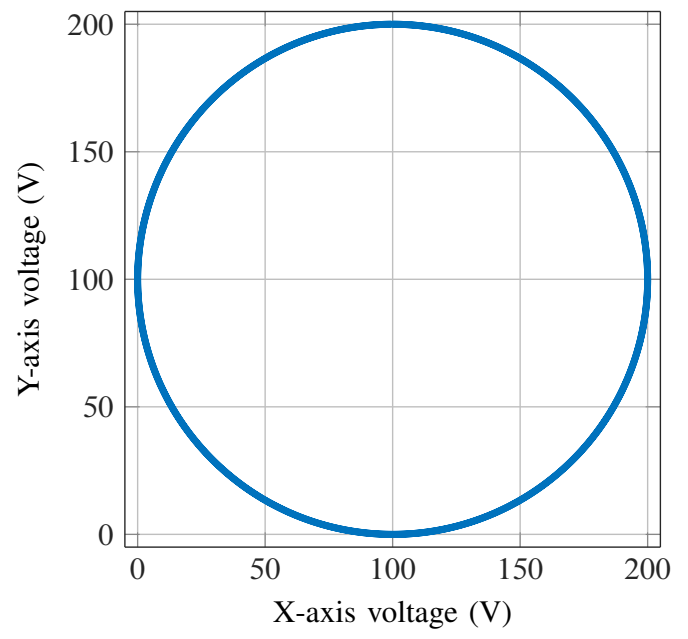

(b)

Fig. 2. Sine and cosine voltage signals applied to the actuators, normalized to their period (a) and ideal spatial trajectory obtained (b)

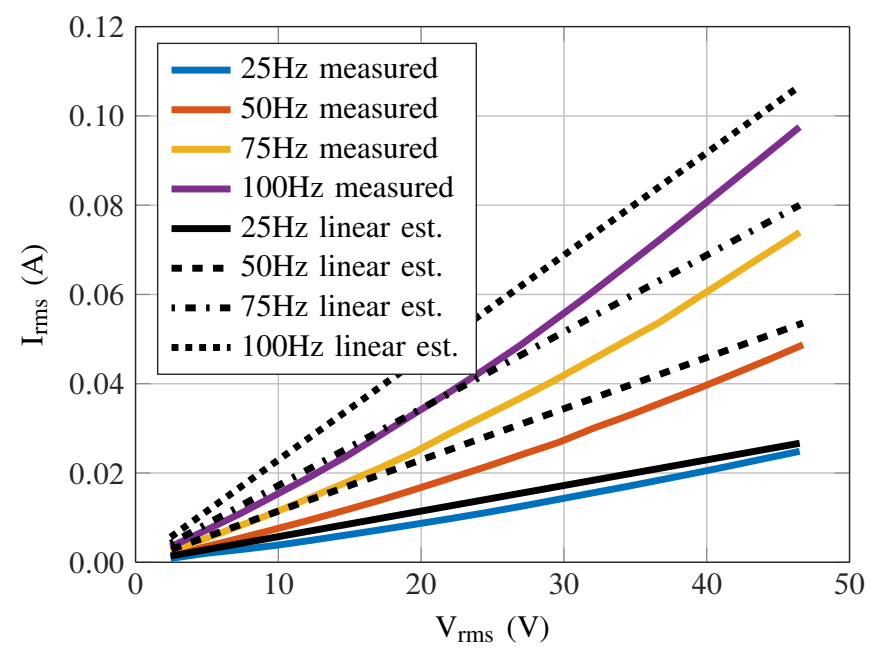

(a)

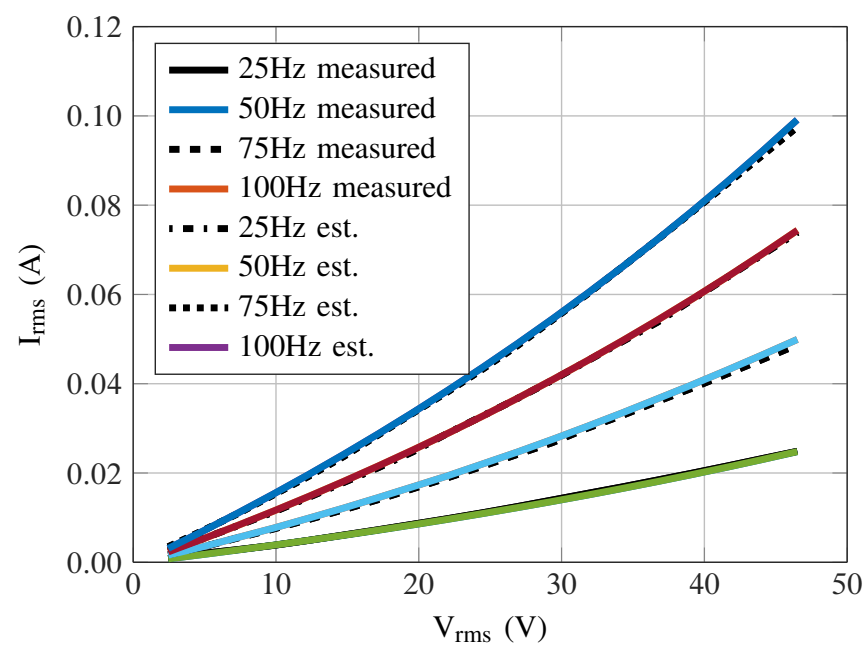

(b)

Fig. 4. large signal model of the stacks: normal model (a), and the proposed improved model (right).

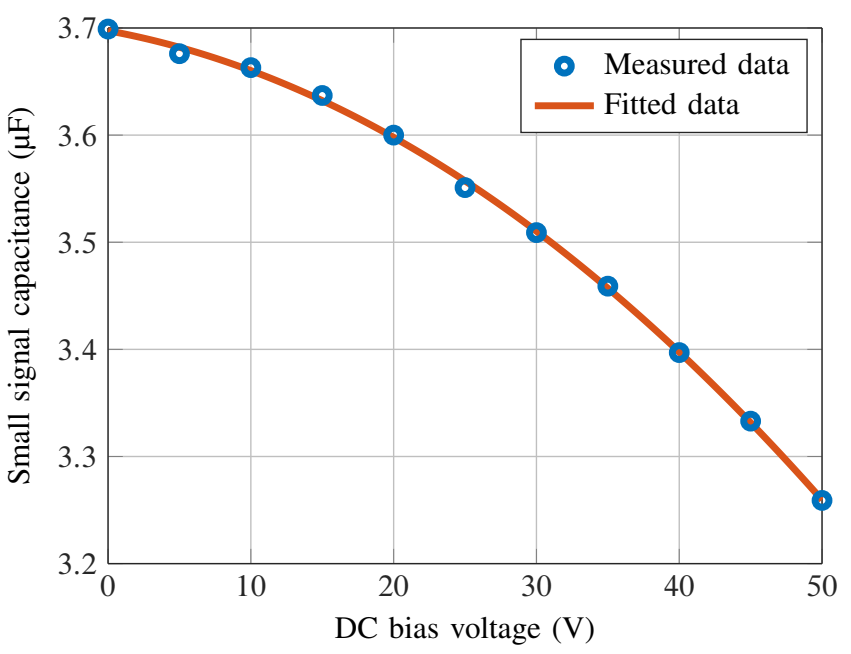

Fig. 3. Derating of small-signal capacitance with the increase of dc voltage. free standing piezo stack is measured with a $100 \mathrm{~Hz}, 1 \mathrm{~V} \mathrm{rms}$ excitation signal by OMICRON Lab Bode 100 and Picotest J2130A DC Bias Injector. The result, which shows a similar small signal feature with ceramic capacitors, can be seen in Fig. 3. The normally used LS model is given in (1), where the current (RMS) of piezo stack is approximated by simple linear function of the SS signal capacitance $C_{S S}$ and applied RMS voltage $V_{r m s}$. However, from Fig. 4 a, the measured piezo stack rms currents deviate from the estimated ones based on (1). Therefore, an improved LS model is presented in (2) with an exponential function rather than a linear one, which can more actually predict the load current, as shown in Fig. 4b. The exponential curve is based off of empirical observations of stack behavior. This can then more accurately be used to specify the power driver design.

$$
\begin{aligned}
& i_{r m s}=2 \pi \cdot f \cdot C_{s s} \cdot V_{r m s} \\
& i_{r m s}=2 \pi \cdot f \cdot C_{s s} \cdot\left(a \cdot e^{b \cdot V_{r m s}}-c\right)
\end{aligned}
$$


TABLE I

EMPIRICAL EXPONENTIAL FITTING COEFFICIENTS

\begin{tabular}{c|c|c|r|r|r} 
& $25 \mathrm{~Hz}$ & $50 \mathrm{~Hz}$ & $75 \mathrm{~Hz}$ & $100 \mathrm{~Hz}$ & Avg. \\
\hline \hline $\mathrm{a}$ & 51.26 & 45.02 & 45.72 & 42.65 & 46.16 \\
$\mathrm{~b}$ & 0.013 & 0.014 & 0.014 & 0.015 & 0.014 \\
$\mathrm{c}$ & 51.62 & 45.31 & 46.03 & 42.87 & 46.46 \\
\hline
\end{tabular}

TABLE II

DRIVER DESIGN SPECIFICATIONS

\begin{tabular}{c|c} 
Specification & Value \\
\hline \hline Input voltage & $200 \mathrm{Vdc}$ \\
Modulation index M & $0.1-0.9$ \\
Output voltage & $20 \mathrm{~V}-180 \mathrm{~V}$ \\
Switching frequency $f_{s}$ & $100 \mathrm{kHz}$ \\
Output frequency & $0 \mathrm{~Hz}-200 \mathrm{~Hz}$ \\
Maximum motor torque $\tau$ & $2 \mathrm{~N} \cdot \mathrm{m}$ \\
\hline
\end{tabular}

where the coefficients $\mathrm{a}, \mathrm{b}$ and $\mathrm{c}$ are obtained by averaging the fitted parameter with four diverse operating frequencies as listed in Table I.

\section{DRIVER STAGE}

A bidirectional Buck converter illustrated in Fig. 5 is adopted as the power driver in this study. The specifications are listed in Table II. Therefore, based on the LS model given above, the output power per axis as a function of torque and output frequency, and equivalent load resistance as a function of output power are plotted in Fig. 6. Then the maximal delivered power of the driver can be calculated, from which the switching devices and the output inductor can be selected. With the output inductor $L$ of $270 \mu \mathrm{H}$, the inductor current ripple-to-average ratio (RAR) at $f=200 \mathrm{~Hz}$ and $\tau=2 \mathrm{~N} \cdot \mathrm{m}$ is shown in Fig. 7, where the factor 2 is marked with a red line. With output frequency $f$ decreasing, the RAR will much larger than 2 . In this case the inductor current direction reverses twice during every switching period and the power switches can operate under ZVS condition.

\section{CONTROL}

The control strategy is an average current control mode. As shown in Fig. 8, an inner current loop regulates the

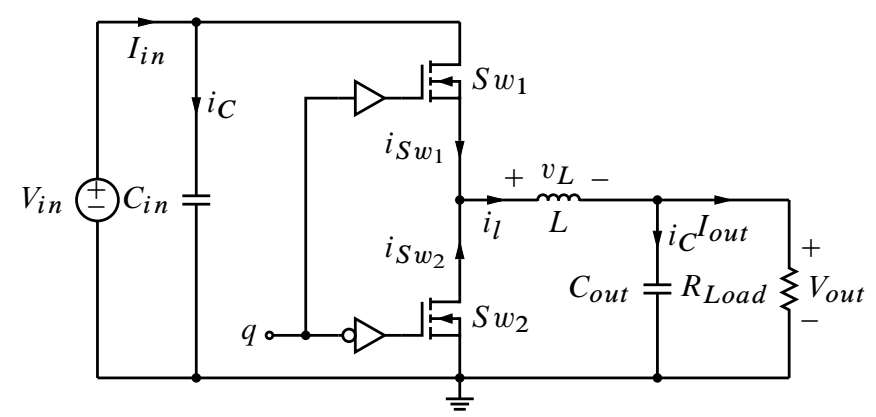

Fig. 5. Synchronous buck converter.

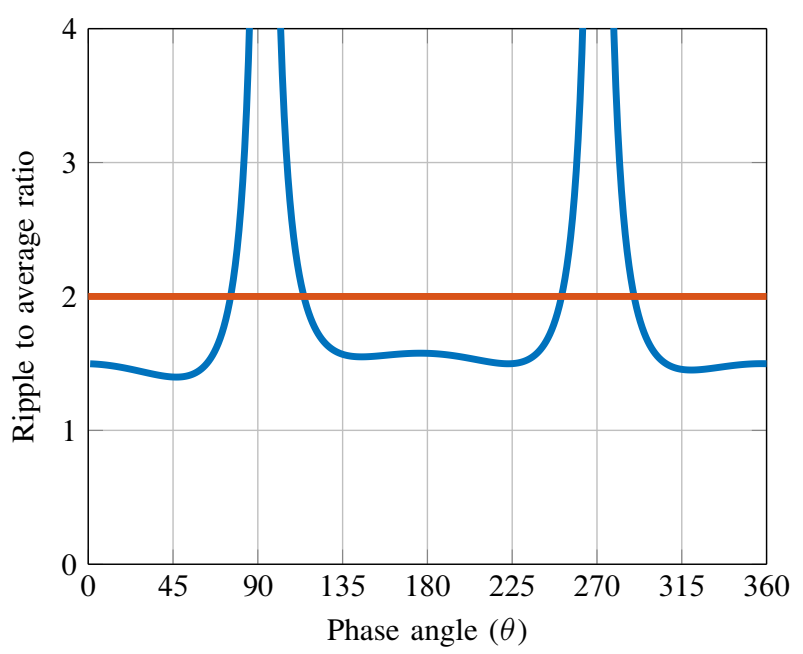

Fig. 7. Inductor current ripple-to-average ratio.

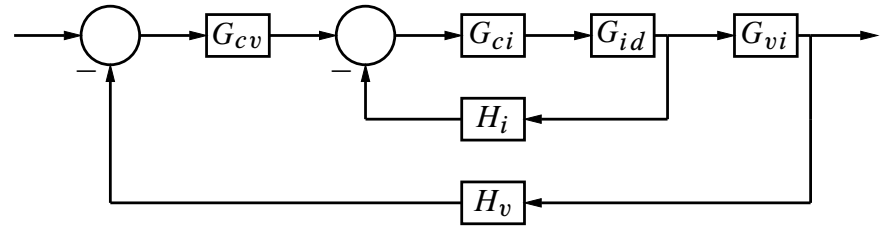

Fig. 8. Block diagram of the closed-loop system

inductor current while an outer voltage loop regulates the output voltage, where $G_{i d}$ and $G_{v i}$ represent the SS transfer functions of duty cycle to inductor current and inductor current to output voltage, respectively. The current compensator is a PID controller to achieve an adequate phase margin, since the sampling and hold process as well as the computational delay contributes a negative effect on phase response. The outer voltage compensator is simply a $\mathrm{P}$ controller to avoid overshoot. The transfer functions of the controllers are shown in (3) and (4)

$$
\begin{aligned}
G_{c i} & =\frac{0.1393-0.1748 z^{-1}+0.0548 z^{-2}}{1-1.043 z^{-1}+0.0432 z^{-2}} \\
G_{c v} & =2.875
\end{aligned}
$$

The frequency responses of the plant and the designed controllers are presented in Fig. 10 and the digital realization is implemented as shown in Fig. 9.

\section{EXPERIMENTAL RESULTS}

In order to verify the analysis, a prototype is built as shown in Fig. 11, and also the thermal measurement under full load from an infrared camera is presented in Fig. 12, where the maximum temperature stays below $60^{\circ} \mathrm{C}$. Output voltage waveforms at lowest and highest frequencies tested are shown in Fig. 14. Moreover, a X-Y voltage plot of the two outputs under frequencies ranging from $10 \mathrm{~Hz}-250 \mathrm{~Hz}$ is shown in Fig. 13, which verifies the voltage control performance of the driver. To verify that the motor is truly working in closed loop, 


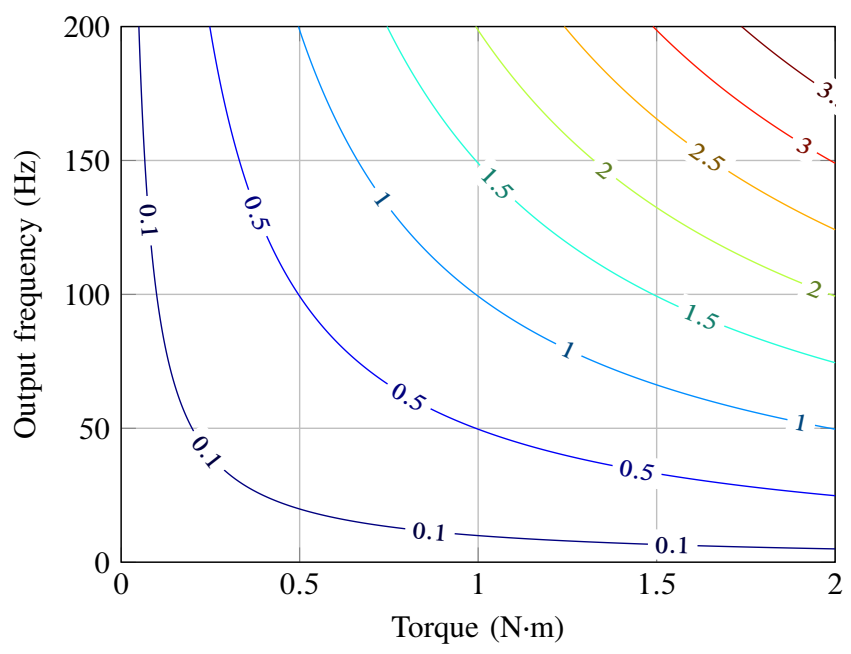

(a)

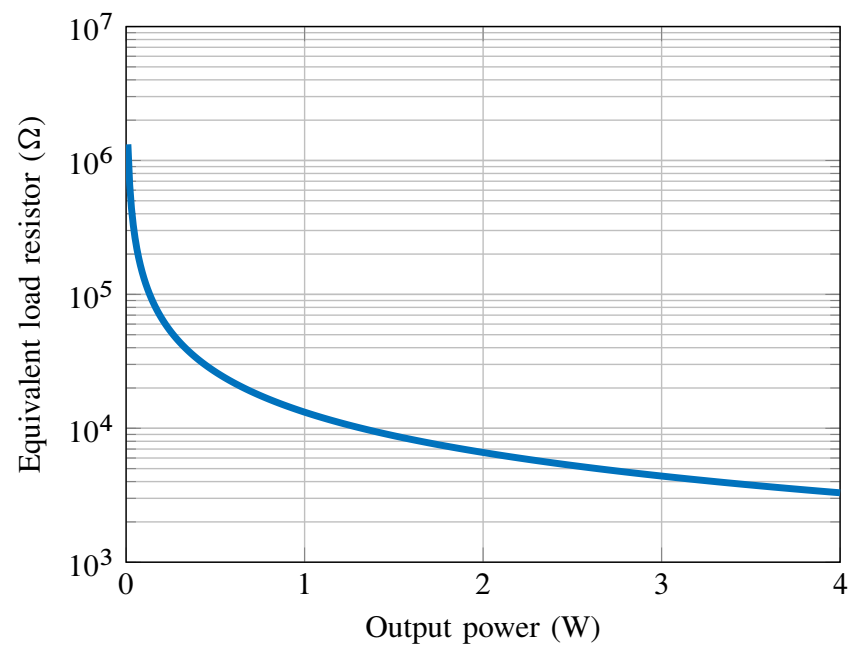

(b)

Fig. 6. Output power of the driver and equivalent load resistance.

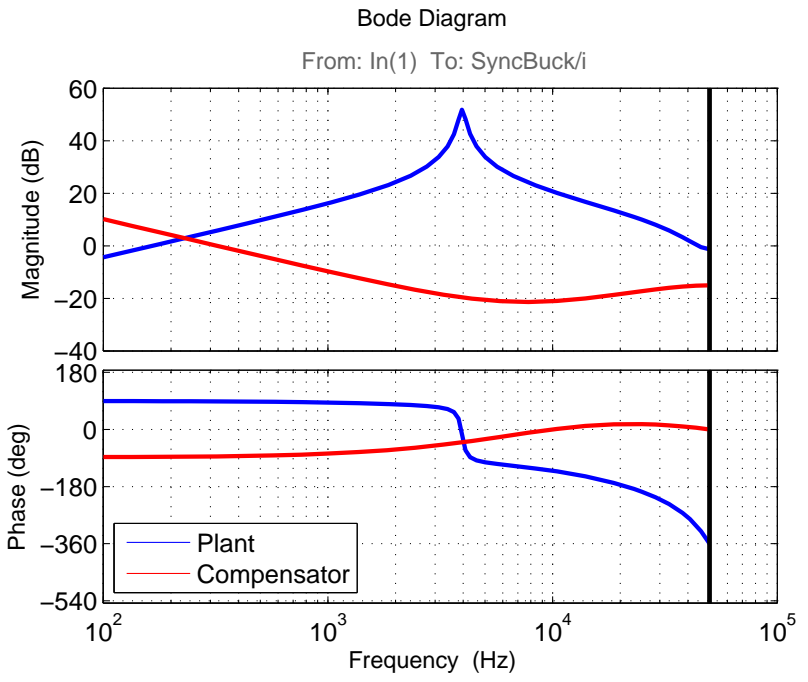

(a)

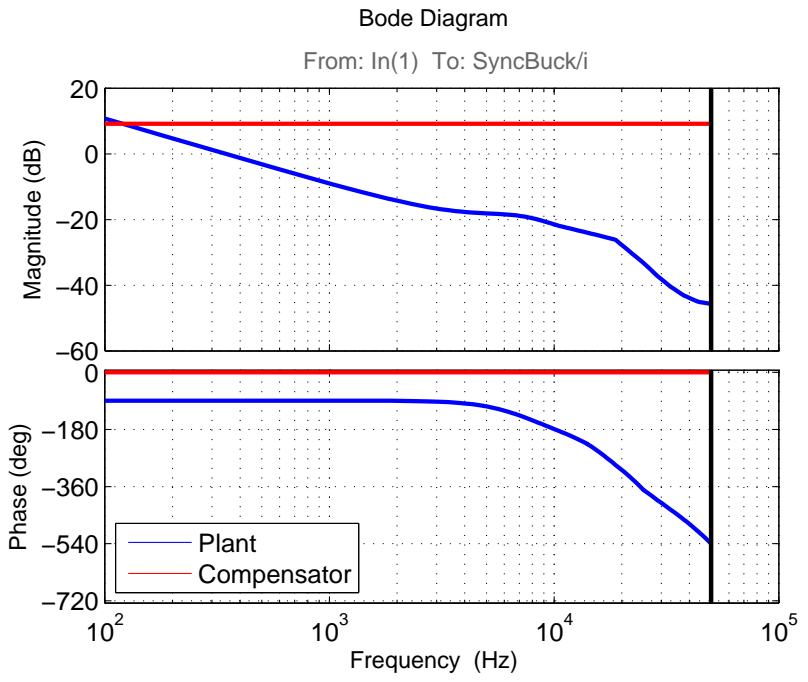

(b)

Fig. 10. Open loop response of uncompensated current loop (blue) and designed compensator (red) (a) and response of uncompensated voltage loop (blue) and designed compensator (red) (b).

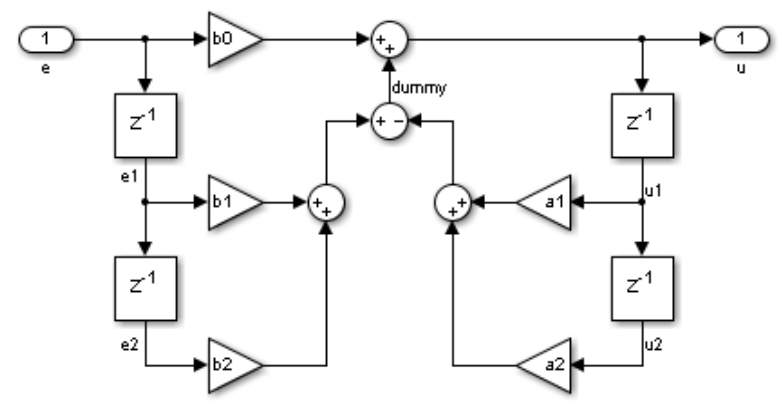

Fig. 9. Realization diagram of implemented digital controller.

its response to signal disturbances is tested. As the system is only tested without external load the only disturbances that can be tested are changes in input voltage. Fig. 15 shows the output response to the input voltage step from $200 \mathrm{~V}$ to $250 \mathrm{~V}$, and there is no significant voltage change in output voltage which means the control loop works effectively. Finally, the power loss in the PAD system including the driver and the motor has been measured and shown in Fig.16. It can be seen clearly that the converter loss increases with increasing output frequency.

\section{CONCLUSION}

This work presents the implementation of a digitally controlled Class-D switch mode driver to drive a PAD motor. The piezo elements of the motor have been analyzed with both small and large signals. The motor is a highly capacitive load with a capacitance increase of up to $100 \%$ at large signals. Due to the capacitive nature of piezo actuators, the power 


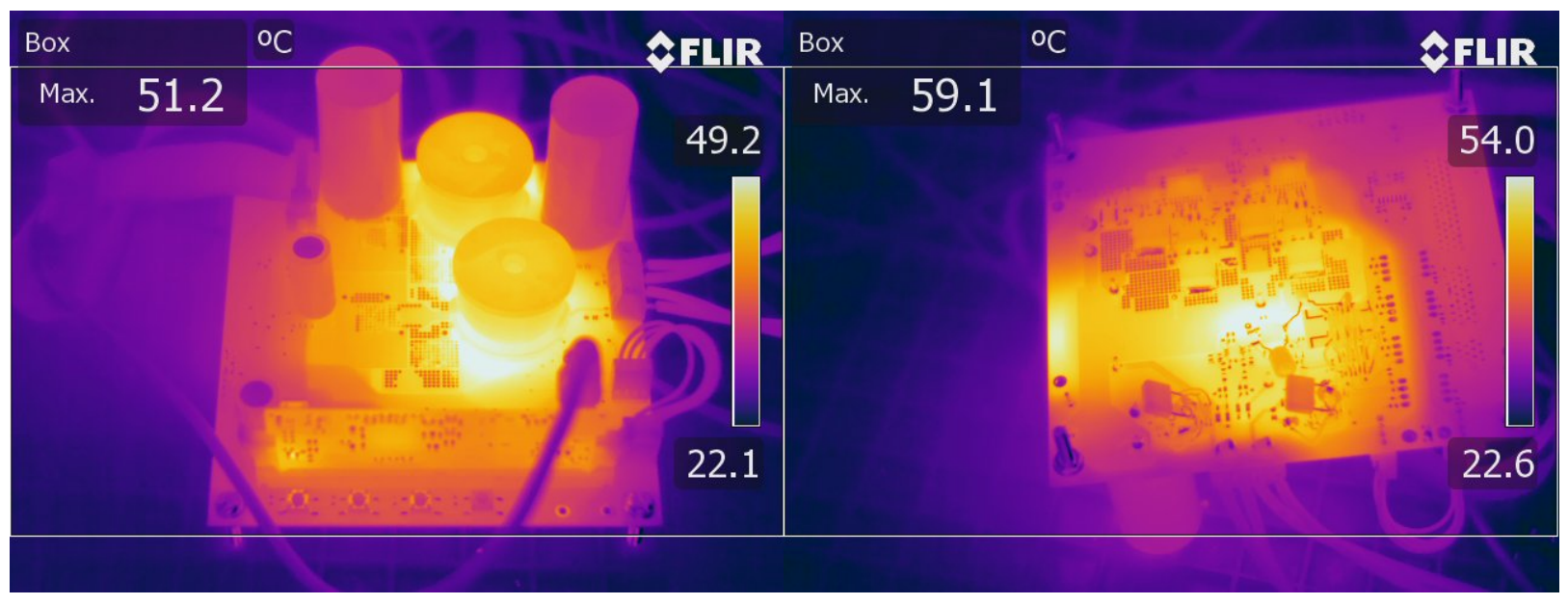

(a)

(b)

Fig. 12. Thermal image of converter running at full load. Top (a) and bottom (b) show maximum operating temperature to be below $60{ }^{\circ} \mathrm{C}$.

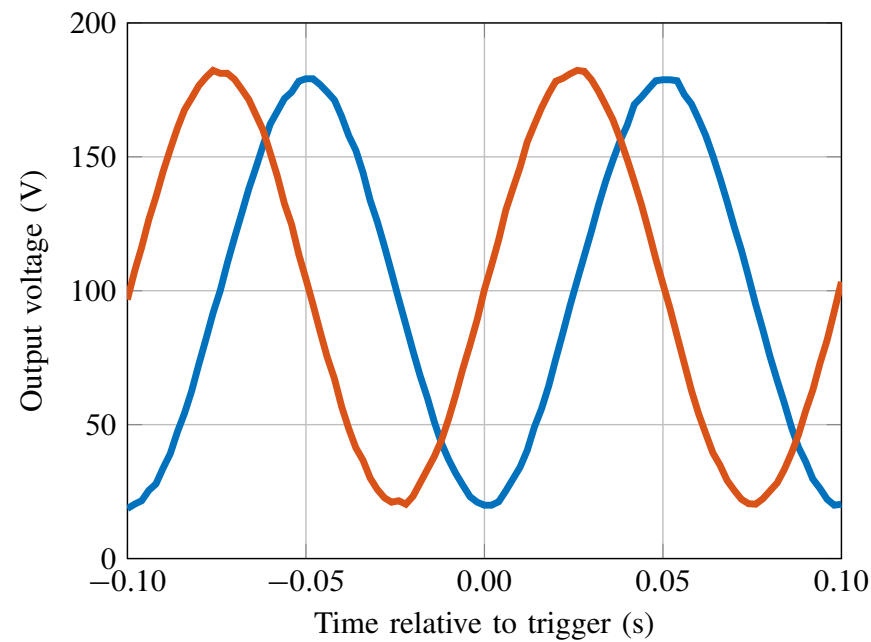

(a)

Fig. 14. Plot of voltage waveforms versus time at $10 \mathrm{~Hz}$ (a) and $250 \mathrm{~Hz}$ (b).

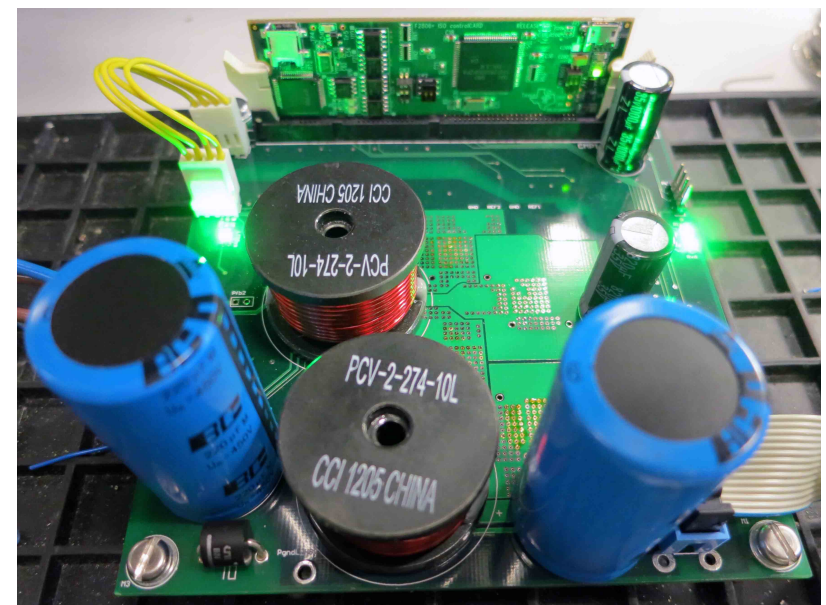

Fig. 11. Image of the designed prototype.

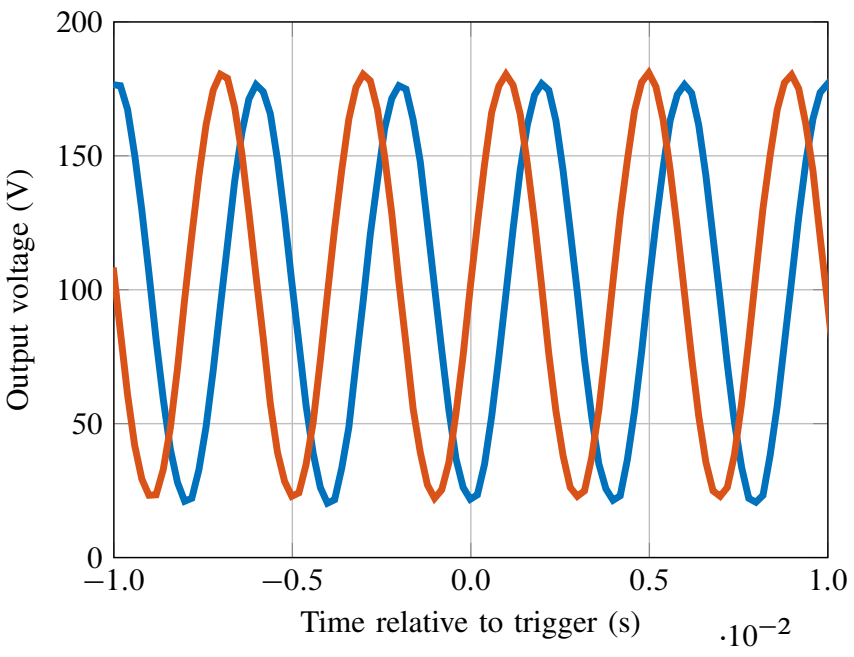

(b)

driver has to been designed physically large relative to the active power it processes. A discrete closed loop controller is implemented on the digital signal controller. Measurement results show that the PAD has been driven with up to $250 \mathrm{~Hz}$ and the THD over the entire frequency range is from $0.9 \%$ to $1.4 \%$. The PAD was not pushed any further in frequency due to the high loss on the piezoelectric stacks. It would be interesting to optimize the driver in terms of size and power efficiency in future research work.

\section{REFERENCES}

[1] A. I. Colli-Menchi and E. Sanchez-Sinencio, "A high-efficiency selfoscillating class-d amplifier for piezoelectric speakers," IEEE Trans. Power Electron., vol. 30, no. 9, pp. 5125-5135, 2015.

[2] B. Ducharne, L. Garbuio, M. Lallart, D. Guyomar, G. Sebald, and J.Y. Gauthier, "Nonlinear technique for energy exchange optimization in piezoelectric actuators," IEEE Trans. Power Electron, vol. 28, no. 8, pp. 3941-3948, 2013.

[3] R.-J. Wai and C.-H. Tu, "Design of total sliding-mode-based genetic algorithm control for hybrid resonant-driven linear piezoelectric ceramic motor," IEEE Trans. Power Electron., vol. 22, no. 2, pp. 563-575, 2007. 


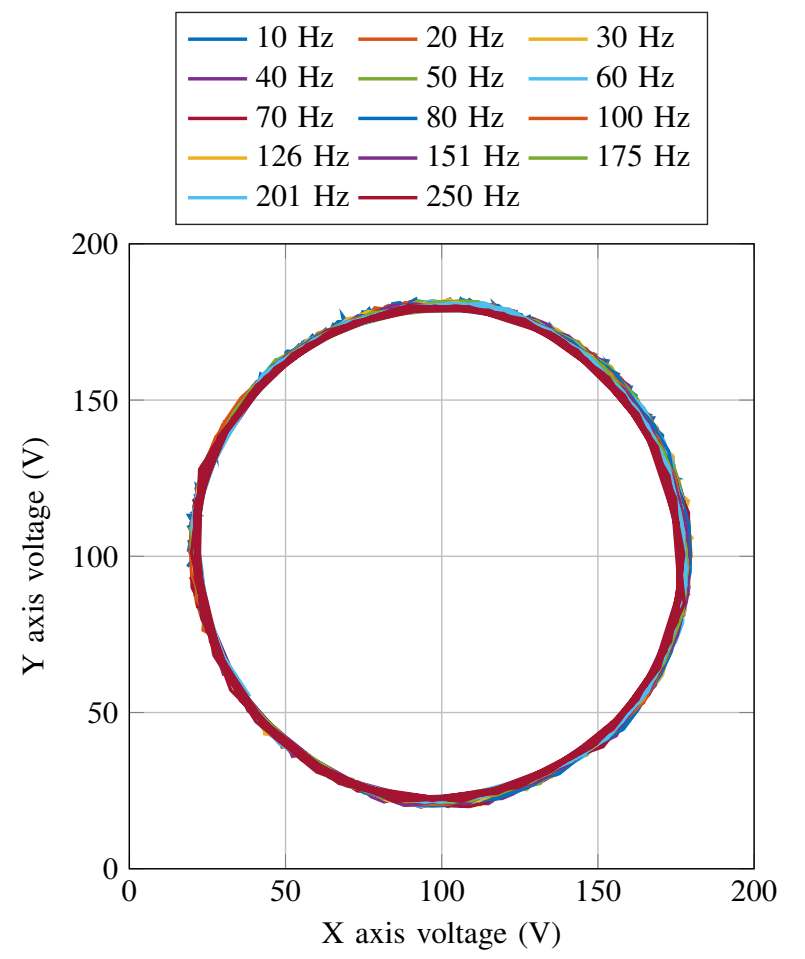

Fig. 13. Derating of small-signal capacitance with the increase of dc voltage.

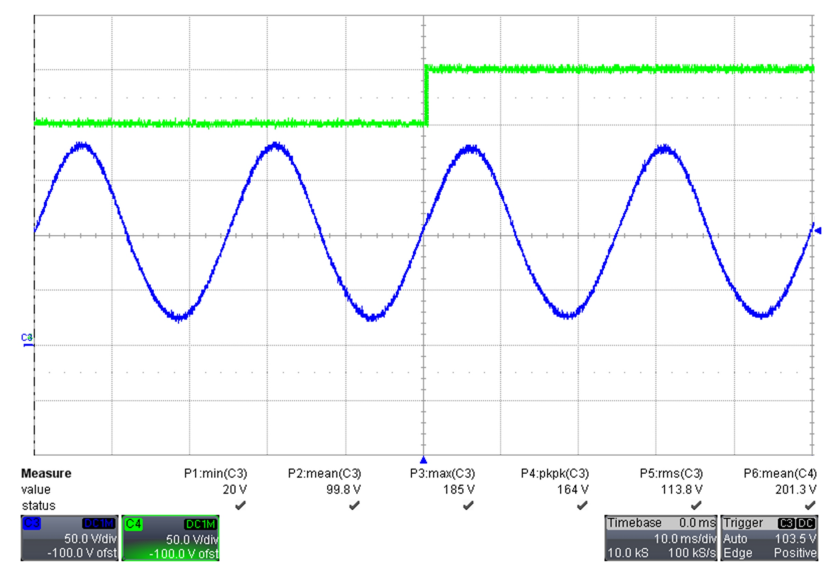

Fig. 15. Response to input voltage step.

[4] E. Goenaga, J.-P. Ferrieux, and J. Barbaroux, "Contactless power transfer system for high power piezoelectric actuators in aeronautical applications," IEEE Applied Power Electronics Conf. and Exhibition, Proc., pp. 3172-3179, 2013.

[5] S. Ben-Yaakov, E. Rozanov, T. Wasserman, T. Rafaeli, L. Shiv, and G. Ivensky, "Resonant driver for a piezoelectric motor with single transistor direction switches," IEEE Applied Power Electronics Conf. and Exposition, Proc., vol. 2, pp. 1037-1043, 2000.

[6] P. A. Sente, F. M. Labrique, and P. J. Alexandre, "Efficient control of a piezoelectric linear actuator embedded into a servo-valve for aeronautic applications." IEEE Trans. Ind. Electron., vol. 59, no. 4, p. 1971, 2011.

[7] N. Bonnail, D. Tonneau, F. Jandard, G. Capolino, and H. Dallaporta, "Variable structure control of a piezoelectric actuator for a scanning tunneling microscope," IEEE Trans. Ind. Electron., vol. 51, no. 2, pp. 354-363, 2004.

[8] S. Huang, K. K. Tan, and T. H. Lee, "Adaptive sliding-mode control of piezoelectric actuators," IEEE Trans. Ind. Electron., vol. 56, no. 9, pp. 3514-3522, 2009.

[9] M. C. W. Hoyerby and M. A. E. Andersen, "Carrier distortion in hysteretic self-oscillating class-d audio power amplifiers: Analysis and

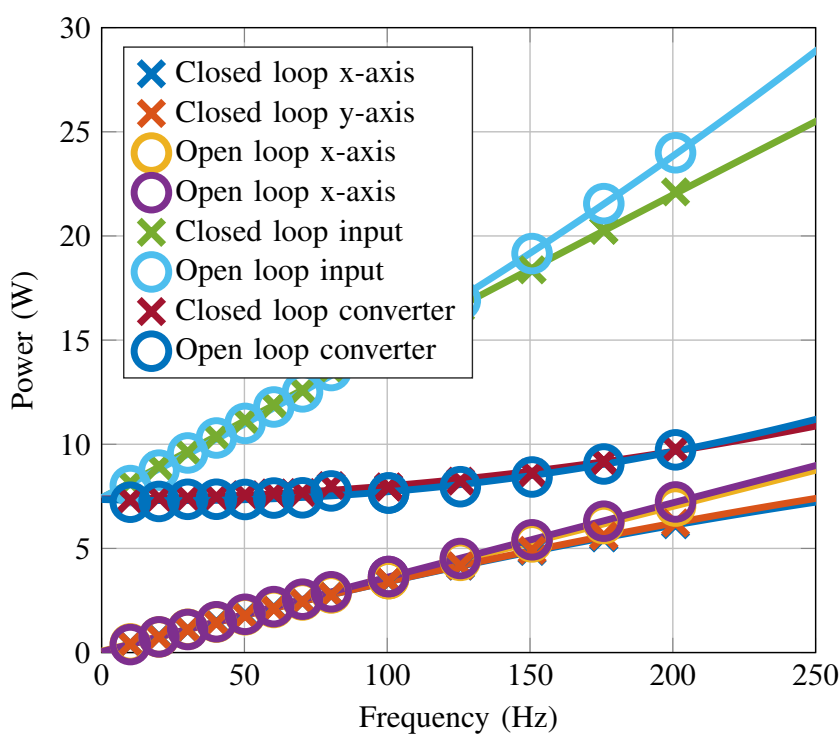

Fig. 16. Derating of small-signal capacitance with the increase of dc voltage

optimization," IEEE Trans. Power Electron, vol. 24, no. 3-4, pp. 714 729, 2009.

[10] A. Oliva, S. Ang, and G. Bortolotto, "Digital control of a voltage-mode synchronous buck converter," IEEE Trans. Power Electron, vol. 21, no. 1, pp. 157-163, 2006. 